\title{
CONTINUITY OF GENERALIZED RIESZ POTENTIALS FOR DOUBLE PHASE FUNCTIONALS
}

\author{
TAKAO OHNO AND TETSU SHIMOMURA
}

Abstract. In this note, we are concerned with the continuity of generalized Riesz potentials $I_{\rho, \mu, \tau} f$ of functions in Morrey spaces $L^{\Phi, v, K}(X)$ of double phase functionals over bounded nondoubling metric measure spaces.

Mathematics subject classification (2020): 31B15, 46E35.

Keywords and phrases: Riesz potentials, Morrey spaces, double phase functionals, continuity, nondoubling measure.

\section{REFERENCES}

[1] P. Baroni, M. Colombo And G. Mingione, Regularity for general functionals with double phase, Calc. Var. Partial Differential Equations 57 (2018), no. 2, paper no. 62, 48 pp.

[2] A. BJÖRN AND J. BJÖRN, Nonlinear potential theory on metric spaces, EMS Tracts in Mathematics, 17. European Mathematical Society (EMS), Zurich, 2011.

[3] S. S. BYUn, S. LiAng AND S. Zheng, Nonlinear gradient estimates for double phase elliptic problems with irregular double obstacles, Proc. Amer. Math. Soc. 147 (2019), 3839-3854.

[4] M. Colombo And G. Mingione, Regularity for double phase variational problems, Arch. Rat. Mech. Anal. 215 (2015), 443-496.

[5] M. Colombo And G. Mingione, Bounded minimizers of double phase variational integrals, Arch. Rat. Mech. Anal. 218 (2015), 219-273.

[6] ERIDAni, H. Gunawan, E. NAKai And Y. Sawano, Characterizations for the generalized fractional integral operators on Morrey spaces, Math. Ineq. Appl. 17 (2014), no. 2, 761-777.

[7] C. De FilipPis And G. Mingione, Manifold constrained non-uniformly elliptic problems, J. Geom. Anal. 30 (2020), no. 2, 1661-1723.

[8] C. De FilipPis and G. PAlatucci, Hölder regularity for nonlocal double phase equations, J. Differential Equations 267 (2019), no. 1, 547-586.

[9] P. HaRjulehto And P. HëstÖ, Boundary regularity under generalized growth conditions, Z. Anal. Anwend. 38 (2019), no. 1, 73-96.

[10] P. HÄstö And J. OK, Calderón-Zygmund estimates in generalized Orlicz spaces, J. Differential Equations 267 (2019), no. 5, 2792-2823.

[11] F.-Y. Maeda, Y. Mizuta, T. Ohno And T. Shimomura, Boundedness of maximal operators and Sobolev's inequality on Musielak-Orlicz-Morrey spaces, Bull. Sci. Math. 137 (2013), 76-96.

[12] F.-Y. Maeda, Y. Mizuta, T. Ohno ANd T. Shimomura, Sobolev's inequality inequality for double phase functionals with variable exponents, Forum Math. 31 (2019), 517-527.

[13] Y. Mizuta, E. Nakai, T. Ohno And T. Shimomura, Campanato-Morrey spaces for the double phase functionals, Rev. Mat. Complut. 33 (2020), 817-834.

[14] Y. Mizuta, E. NaKai, T. Ohno And T. Shimomura, Riesz potentials and Sobolev embeddings on Morrey spaces of variable exponent, Complex Var. Elliptic Equ. 56, no. 7-9, (2011), 671-695.

[15] Y. Mizuta, T. Ohno And T. Shimomura, Sobolev's theorem for double phase functionals, Math. Ineq. Appl. 23 (2020), 17-33.

[16] C. B. Morrey, On the solutions of quasi-linear elliptic partial differential equations, Trans. Amer. Math. Soc. 43 (1938), 126-166. 
[17] J. MusielaK, Orlicz spaces and modular spaces, Lecture Notes in Math. 1034, Springer-Verlag, 1983.

[18] S. Nagayasu And H. Wadade, Characterization of the critical Sobolev space on the optimal singularity at the origin, J. Funct. Anal. 258 (2010), no. 11, 3725-3757.

[19] T. OHNo AND T. SHimomura, Sobolev inequalities for Riesz potentials of functions in $L^{p(\cdot)}$ over nondoubling measure spaces, Bull. Aust. Math. Soc. 93 (2016), 128-136.

[20] C. Peréz, Sharp $L^{p}$-weighted Sobolev inequalities, Ann. Inst. Fourier (Grenoble) 45 (1995), 809824.

[21] E. PUSTYLnIK, Generalized potential type operators on rearrangement invariant spaces, Israel Math. Conf. Proc. 13 (1999), no. 3, 161-171.

[22] Y. Sawano And T. Shimomura, Sobolev embeddings for Riesz potentials of functions in nondoubling Morrey spaces of variable exponents, Collect. Math. 64 (2013), 313-350.

[23] Y. SAWANO AND T. SHImomura, Boundedness of the generalized fractional integral operators on generalized Morrey spaces over metric measure spaces, Zeit. Anal. Anwend. 36 (2017), 159-190.

[24] Y. SAWANO AND T. SHImomuRA, Generalized fractional integral operators over non-doubling metric measure spaces, Integral Transforms and Special Functions, 28 (2017), 534-546.

[25] Y. Sawano, S. Sugano And H. TANaKa, Orlicz-Morrey spaces and fractional operators, Potential Anal. 36 (2012), no. 4, 517-556.

[26] P. SHIN, Calderón-Zygmund estimates for general elliptic operators with double phase, Nonlinear Anal. 194 (2020), 111409, 16 pp.

[27] V. V. ZHIKOV, Averaging of functionals of the calculus of variations and elasticity theory, Izv. Akad. Nauk SSSR Ser. Mat. 50 (1986), 675-710. 